\title{
A Study on Determinant Factors in Smart City Development: An Analytic Hierarchy Process Analysis
}

\author{
Seunghwan Myeong ${ }^{1, *(\mathbb{D})}$, Yuseok Jung ${ }^{2,+}$ and Eunuk Lee ${ }^{2,+}$ \\ 1 Department of Public Administration, Inha University, Nam-gu, Incheon 402-751, Korea \\ 2 Department of Global e-Governance, Inha University, Nam-gu, Incheon 402-751, Korea; \\ jungys@inha.edu (Y.J.); utopia.hoho@gmail.com (E.L.) \\ * Correspondence: shmyeong@inha.ac.kr \\ + These authors contributed equally to this work.
}

Received: 17 May 2018; Accepted: 20 July 2018; Published: 25 July 2018

\begin{abstract}
Today, there are many discussions and guidelines on the issue of smart cities (meaning cities that introduced smart technology) from the perspective of traditional urban policy. Smart city policies focusing on technology have been criticized for eliminating the different levels of factors that surround smart cities. When governments fail to consider different factors in implementing smart policies, they might not effectively provide quality services to citizens, because smart cities involve not only technical elements, but also the complex elements surrounding them (e.g., the policy ecosystem and urban infrastructure). This exploratory study examines the determinants of smart cities and their priorities through an analytic hierarchy process analysis. In this study, the priority internal factors appeared in the order of citizen involvement, leadership, and infrastructure, and the priority external factors took the order of political will, stakeholders, and the fourth Industrial Revolution. In addition, this study shows that the presence of communication channels, public hearings, and direct stakeholders is important for analyzing each sub-factor.
\end{abstract}

Keywords: smart city; AHP analysis; smart city decision factors

\section{Introduction}

Around the world, urbanization is being progressed more rapidly than ever before. The global urbanization rate exceeded $50 \%$ in 2007 , and is expected to exceed $70 \%$ by 2050 . The urban population, which was 1.4 billion in 1970, will increase to 6.3 billion by 2050 , with $60 \%$ of the world's population expected to be concentrated in urban areas [1]. This has led to various ongoing discussions about how to solve new urban problems. Smart cities are one of the most sought after solutions. The smart city is a conceptual urban development model, which means city construction based on information and communication technology (ICT). The specific definition of a smart city differs according to the economic level and the city policy of the country, but it can be seen as a city that uses ICT to improve city competitiveness and quality of life, and pursue urban sustainability. As interest in smart cities grows, many countries are spurring their construction. China plans to invest two trillion yuan (about US $\$ 333$ billion) by 2025 to transform $80 \%$ of its cities into smart cities. Since 2010, Japan has invested approximately 68 billion yen in smart city-related policies to rebuild cities in the regions that were affected by the Great East Japan Earthquake. In 2015, the White House announced a smart city plan that included a $\$ 160$ million research and development (R\&D) investment plan to solve various urban problems [2]. Navigant Research's study reflects this trend, and the global smart city market is expected to grow steadily, more than doubling from $\$ 424$ billion in 2017 to $\$ 12$ trillion in 2020 [3]. 
Innovation in ICT has always been at the heart of the implementation of new cities, including smart cities. In fact, since smart cities were introduced, many different cities have discussed the development of ICT, using terms such as "virtual", "intelligent", "digital", and "ubiquitous" [4]. As a result, in many studies, smart cities also focused on improving urban systems by using advanced technology. For example, the term "smart city" was first used in the 1990s; at that time, many studies focused on the importance of new ICTs in relation to modern infrastructure in cities. In other words, they focused on how smart communities could be smarter, and cities could be designed to implement information technology [5].

In contrast, some studies have criticized technology-oriented smart cities. Research studies on the roles of human capital, education, social and relational capital, environmental interests, smart city management, and leadership as important driving forces for urban growth are typical examples [6-10]. Nevertheless, many studies related to smart cities are still focused on technological innovation, and there are few studies that deal with the different levels of the factors that influence the building of a smart city [6]. In this situation, it is important to look at the variety of factors that influence smart cities, and search for the priorities in building desirable smart cities through a comparison of the factors. Therefore, this study examines the internal and external determinants related to smart cities, and analyzes what factors need to be focused on.

The composition of this paper is as follows. The second section looks at the theoretical background of the concept of smart cities and their determinants. Section 3 describes the research methodology and the process of factoring. In Section 4 , the analysis is conducted using a questionnaire based on the research model, and the analysis results are explained. The main factors, sub-items and details are analyzed using AHP (Analytic Hierarchy Process) methodology. Finally, Section 5 discusses the policy implications of the study, and suggests policy alternatives as well as future research directions.

\section{Literature Review}

\subsection{Smart City Concepts}

Smart cities involve various concepts in academia, governments, global corporations, and international organizations. In other words, there is no consensus on the concept of a smart city.

Hollands [11] discussed the difficulties of establishing a smart city concept by explaining the hidden factors involved in the labeling of smart cities. First, the definition of smart cities has not been refined since 2000, and no new elements have been added. Second, there have been various studies on ICT, but the concept of quality of life is still uncertain, and the link between smart technology and quality of life has not been clearly established. Finally, he explained that the meaning of "smart" and its connection to cities remain ambiguous.

Hall [12] mentioned that the vision of "smart cities" is one of urban centers of the future made safe, secure, environmentally friendly, and efficient because all of the structures-whether for power, water, transportation, etc.-are designed, constructed, and maintained while making use of advanced integrated materials, sensors, electronics, and networks that are interfaced with computerized systems comprising databases, tracking technology, and decision-making algorithms.

Bakic1 et al. [13] argued that a smart city is a tech-intensive and advanced city that connects people, information, and city elements using new technologies in order to create a sustainable, greener city that features competitive and innovative commerce and an increased quality of life.

Giffinger [14] insisted that a smart city is a smart society in which various elements such as people, the environment, mobility, governance, and the economy are built within a smart infrastructure.

On the other hand, citizens must be included in a smart city. Citizens are a key element of smart cities as they form such a city through continuous interactions. For this reason, a smart populace is recognized as a key driver of smart cities; so education, learning, and knowledge are important strategies in smart cities [15]. In addition, social infrastructures such as intellectual capital and social capital can be seen as essential elements of smart cities because they connect people and form 
relationships [5]. Yigitcanlar et al. [16] found six subthemes as determinants of a smart city by reviewing 78 journal articles including 'productivity', 'sustainability', 'accessibility', 'well-being', 'liveability', and 'governance', which are considered desired outcomes of smart cities. Accordingly, the concept of a smart city implies a complex mixture of education, culture, art, business, economy, and commerce.

While there are a variety of views on the definition of a smart city, it is clear that a smart city adopts new technologies in order to improve the level of efficiency associated with utilizing urban infrastructure functions. A smart city also seeks to improve the quality of life of its citizens. Thus, the concept of a "smart city" can be defined as "a city that is sustained based on highly intelligent ICTs and social networking; communication between people and things and things and things, which goes beyond time and space; convergence between ICT and real time; and convergence with other industries by which new value-added contents and services are constantly re-created accompanied by innovation of society as a whole, including work styles, lifestyles, culture, politics, and the economy".

\subsection{Smart City Diagnosis Index Analysis}

The previous studies on smart cities mostly focused on analyzing the key factors in the field of technology and technical infrastructure. Using the existing smart city diagnostic index, it is possible to check what items or services are included in the diagnosis index and which services are evaluated in existing smart cities. Currently, it is based on the smart city index developed by various institutions and researchers, because there is no standard for analyzing the smart city.

A Study on Construction and Application Approaches of Smart City Maturity and Potential Diagnostic Models from the National Institute of Land Research of Korea in 2016 analyzed those smart city diagnostic indexes as shown in Table 1. In this study, diagnostic indexes in Europe tend to lose their smart city centered on technology, systems, and human factors, but the majority of indexes in Korea focus on maximizing the function of urban infrastructure by ICT. In this study, the contents of the questionnaire of the existing diagnostic indexes were analyzed and reconstructed into the categories of Table 2. Analyzing the items of the Smart City index used, we analyzed the frequency of the items with the same characteristics.

Table 1. Smart city diagnosis indexes.

\begin{tabular}{ccl}
\hline No. & \multicolumn{1}{c}{ Smart City Index } & \multicolumn{1}{c}{ Remarks } \\
\hline 1 & European Smart City Index & European Union (EU) \\
\hline 2 & Smart City Key Index & Smart Cities Council (SCC) \\
\hline 3 & Navigant Smart City Index & Woods and Gartner \\
\hline 4 & United Kingdom (UK) Smart Cities Index & Navigant \\
\hline 5 & Smart City Maturity Model & International Data Corporation (IDC) \\
\hline 6 & Smart City Index & Integrated Electronics (INTEL) \\
\hline 8 & Smart Sustainable City Index & International Telecommunication Union (ITU-T) \\
\hline 9 & Smart City Performance Measure & International Organization for \\
\hline 10 & Standardization/International Electrotechnical \\
\hline 11 & Smart City Index & Commission (ISO/IEC) \\
\hline
\end{tabular}


Table 2. Smart city performance evaluation index frequency.

\begin{tabular}{|c|c|c|}
\hline & Category & Frequency \\
\hline 1 & Economy & (1), (2), (8), (10), (11) \\
\hline 2 & Human Resources & (1), (2) \\
\hline 3 & Governance & (1), (2), (6), (8) \\
\hline 4 & Traffic & (1), (2), (8), (10) \\
\hline 5 & Environment & (1), (2), (7), 8), (10) \\
\hline 6 & Living & (1), (2), (7), (8), (10), (11) \\
\hline 7 & Plan/Strategy & (3), (4), (5), (14) \\
\hline 8 & Execution & (3), (4) \\
\hline 9 & Culture & (5) \\
\hline 10 & Step & (5) \\
\hline 11 & Technology & (5) \\
\hline 12 & Data & (5), (10) \\
\hline 13 & Innovation & (6), (7), (8) \\
\hline 14 & Sustainability & (6) \\
\hline 15 & Social integration & (6) \\
\hline 16 & Information linkage & (6), (10) \\
\hline 17 & Infra & (7), (8), (11) \\
\hline 18 & Crime or disaster prevention & (7) \\
\hline 19 & Citizens (people) & (8), (10), (11) \\
\hline
\end{tabular}

As a result of analyzing the frequency of smart city performance evaluation indexes in the categories, the indexes of the smart city diagnostic model, including Living, Environment, Traffic, Plan/Strategy, and Governance, were found to be high.

There are limitations in that it is difficult to distinguish smart cities from sustainability indicators in the case of major EU-based diagnostic models as well as international cities and green city indexes, because they recognize smart cities as technology and systems, as well as human factors.

In the case of the smart city diagnosis model, there is a tendency to grasp smart cities mainly on Europe's technology, systems, and human factors. On the other hand, most domestic diagnostic models narrowly have focused on the technological factors functioning as an infrastructure building. The Navigant index and the Global System for Mobile Association (GSMA) and Ericsson indexes, which have a mental perspective and evaluating private companies, also have limitations by focusing too much on mobile functions.

Of course, technology infrastructure can be an important factor in developing a smart city, and it is blended with ICT technology. However, we cannot come to conclusions about a good smart city based on the above-mentioned indicators. In order for a city to develop, many factors must be developed in consideration of the internal and external environments, including leadership, organizational structure, governmental system, legal backgrounds, political processes, interest groups, citizen support and participation, local industries and vendor communities, and stakeholders. Smart city planning and development should include non-technological factors such as people's cooperation, governmental policy support, leadership, and local innovation, which is what we want to discuss.

\subsection{Smart City Trend}

According to the report " 5 Ways to Make Our Cities Smarter" [17] by the World Economic Forum, there are five key elements of smart cities as shown in Figure 1: a global outlook and political will, smart standards, smart regulations, public-private partnerships, and local innovation. 


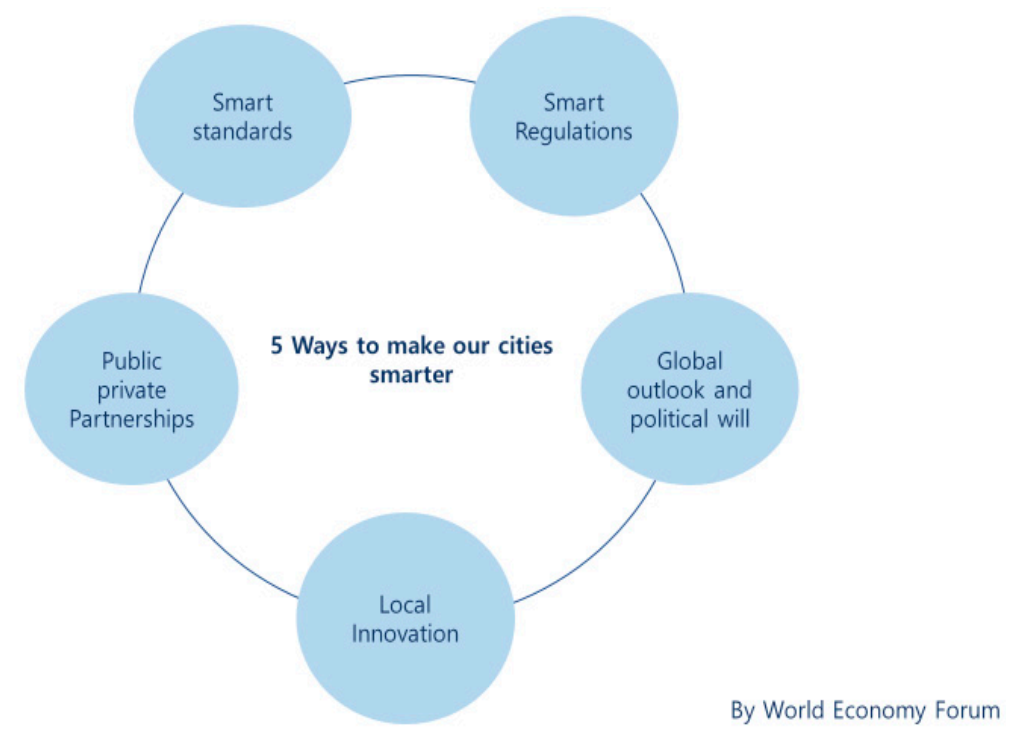

Figure 1. Five ways to make our cities smarter.

The five elements of smart cities mentioned by the World Economic Forum differ from the existing smart city evaluations and indicators, but they are key elements of smart cities. It is very important to understand the global trend of the smart city as well as the political will in the process of building smart cites, which had mentioned in the introduction: many countries are committed to developing smart city around the world. However, smart regulation is necessary as well. Smart regulation should not be an impediment to the development of the smart city, and should be accompanied by government policy efforts so that the smart city can be developed in accordance with government policy. It also explains that it can be a "smarter" city or smart city if the partnership between the public and private sector is established and harmonized.

Currently, various discussions and studies are being conducted in various countries around the world to create their own smart city. Siim Kallas, Vice-President of the European Commission's Transportation Department, said, "Transportation representatives, telecommunications carriers, vehicle manufacturers, city planners, and energy companies all gather together to discuss meaningful discussions about the future of cities in Europe. The Smart City Initiative will bring less congestion and new business opportunities." He also emphasized that we should move to action. Following these political will, great smart cities are in Europe, such as Amsterdam in the Netherlands and Copenhagen in Denmark. Most smart cities are developing with a focus on technology infrastructure such as smart traffic, smart buildings, and smart integrated management. For example, there are many studies focusing on technologies around the world such as smart traffic [18-24], urban planning [17,25-27] and architecture, smart energy systems $[19,20,28-30]$, and so on.

\section{Main Factors}

We have found that many documents focus more on the results than on the smart city construction process. Accordingly, we have drawn inward and outward factors to clarify which determinants should be more important in the process of building smart cities.

In this study, the Analytic Hierarchy Process (AHP) technique was used to prioritize the determinants of smart city. The AHP is a decision-making method that obtains the importance through a pair comparison between attributes constituting a hierarchical structure. The AHP divides the decision-making process into several stages, and then proceeds to the final decision by objectifying the subjective judgment of the evaluator through the step-by-step analysis. This systematically ranks various alternatives and derives them as a percentage scale reflecting the weight. The AHP allows the 
importance of each alternative to be calculated by classifying the importance hierarchically, which is suitable for solving a large number of decision problems [31].

For the selection of smart city decision factors for this study, related literature and a smart city index were analyzed. Citizen participation [10,32-34], leadership [35-37], and infrastructure [38-41] were extracted as internal factors among the determinants of smart city in Section 3.1. We have also derived the fourth Industrial Revolution [42], policy commitment [43], and stakeholders [44] as important factors for smart decision making in Section 3.2. Then, opinions were exchanged on detailed factors through three brainstorming processes. In this section, we summarize the current status of the smart city and urban policy, and set up a hierarchy of smart city determinant factors, as shown in Figure 2.

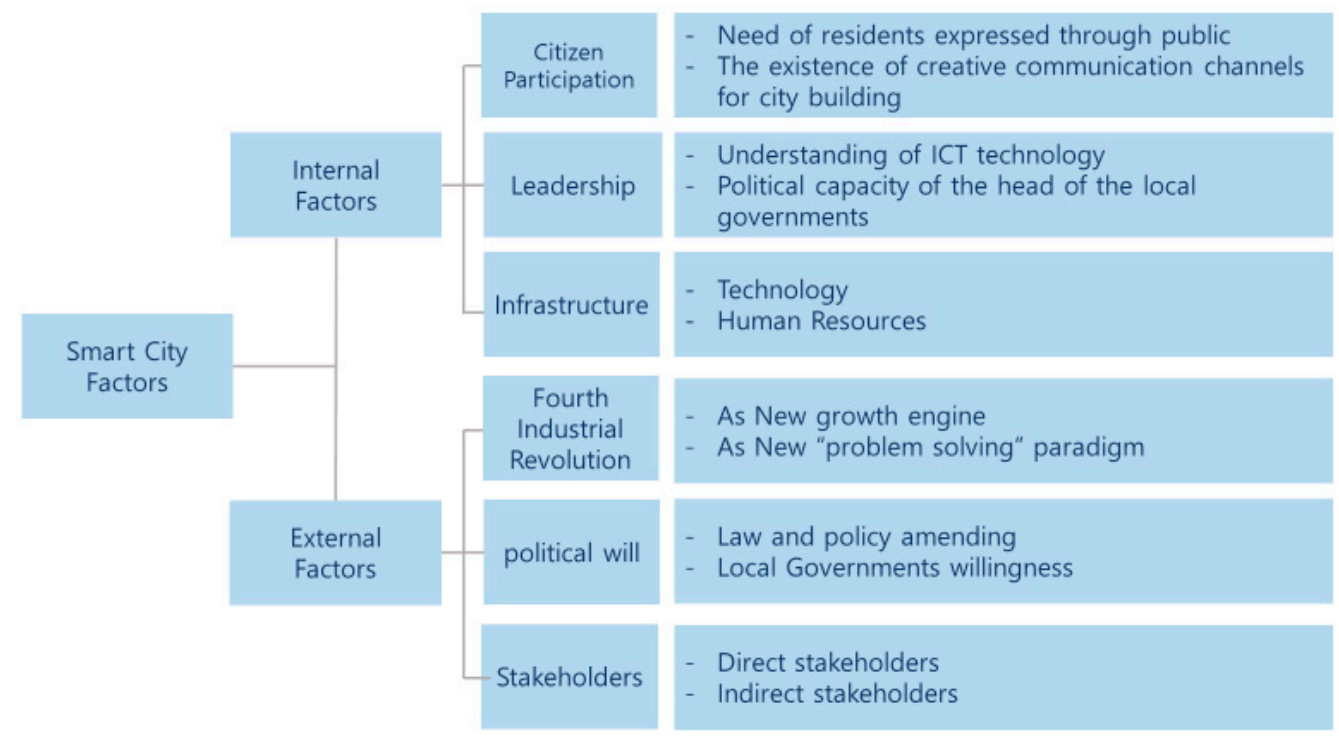

Figure 2. Smart city factor hierarchy.

\subsection{Internal Factors}

\subsubsection{Citizen Participation}

This factor refers to citizen or resident participation in urban policy decisions, not just as beneficiaries of simple urban policy decisions that can directly support their interests. The citizens or residents express their wishes and seek solutions to them; this also relates to the concept of the inhabitants [32].

Margerum [33] argued that for sustainable urban development, the planning and enforcement of planned urban policies are necessary, but that various groups such as citizens and civil society should participate in the formulation and enforcement of such urban policies. Therefore, the activation of citizen participation is essential in enhancing democracy and the efficiency of city policy.

Kim Han-Jun [34] argued that urban planning in the smart era should be expanded and transformed to be different from existing urban planning. The development of ICT has brought about changes in society and human behavior in various fields. In the process of smart city development, it has been argued that the expansion of citizen participation in the form of bottom-up, experimental innovation; open-source platforms; and living labs appeared as a new urban plan.

Deakin [10] said that the greatest virtue of a smart city is turning government-led policy decision making into citizen-led policy decision making. He called for citizens to actively intervene in the practice of social justice and environmental justice in the city by means of advisory groups, debates, civic participation budgets, and civic petitions. 


\subsubsection{Leadership}

In terms of urban policy, the leadership of the local governor has a great influence on the success or failure of the policy. Lee [35] investigated the success factors of lifelong learning city policy in terms of the leadership of local autonomous governments, and concluded that the leadership of the local government heads was able to execute the lifelong learning city policy more successfully, as the leader's political capacity was stronger.

Neirotti et al. [36] argued that the likelihood of increasing the quality level of a smart city depends on country-specific variables. Among them, leadership is argued to affect a smart city's political level, political risk, and corruption level. In order to reduce delays in implementing smart cities, policy makers in leadership roles must find ways to relieve the path dependence on technology adoption.

Washburn et al. [37] also discussed the qualities of leaders in the smart city era. For example, a CIO (chief information officer), as a digital leader, should exercise their influence in smart city building. In particular, CIOs in the smart city era must show leadership featuring ICT knowledge for the sake of successful smart city building, including skills in long-term financing, an appropriate allocation of expertise, employee education, staff accountability, and the standardization and interoperability of systems.

\subsubsection{Infrastructure}

The basis of the smart city concept is the development of ICTs such as wireless communication, big data, and the Internet of Things (IoT). The development of new technologies is realizing things that were not possible in the cities of the past. Smart technologies such as digital devices and Internet networks have been studied continuously, and various innovations and services have been achieved that were each independently developed and then connected with each other [38]. In particular, city concepts such as the digital city, which emerged at the beginning of the discussion of efficient urban problem solving based on ICT, have been almost totally replaced by the concept of the smart city, which aims to operate integrated cities [39].

In other words, urban problem solving using ICT is a major task in smart city building. Toporkoff [40] argued that the development of digital technology affects various areas of a city (notably, there are big changes in urban administration and development), and that the large amount of data generated by various ICT systems is a major factor in smart cities.

Although the technology infrastructure is an important factor of a smart city, the effect of the technology infrastructure might be less if the human infrastructure is not built. For example, even if a power plant is built that produces electricity, it will become useless without human infrastructure that can run it. Building a human infrastructure is important as well as technology infrastructure. This is why we need to educate people in building a smart city for more effectively utilizing the cutting-edge technologies.

\subsection{External Factors}

\subsubsection{The Fourth Industrial Revolution}

The term 'fourth Industrial Revolution' was first introduced at the 47th World Economic Forum Annual Meeting in Switzerland in January 2016. The fourth Industrial Revolution was defined as a next-generation industrial revolution led by artificial intelligence (AI), robotics, and life sciences. It is a technological revolution that combines digital, biotechnology, and physics based on the tertiary industrial revolution [41].

Once the fourth Industrial Revolution arrived, the paradigm for trying to solve complex and diverse urban problems changed. In particular, open innovation within smart city platforms focuses on a decentralized approach to innovation, as it has become apparent that knowledge and expertise cannot be found solely within the government, but rather are widely distributed across various sectors 
of society [42], which we discussed in Section 2.2. Artificial intelligence, IoT, and so on are becoming key elements of smart cities as they are merged with cities.

In Korea, for example, the Korean government is deeply involved in the development of smart cities in response to the fourth Industrial Revolution. In addition, as shown in Figure 3, it expects to solve the existing urban problems through the convergence of ICT technologies and play a key role in revitalizing the economy as a new growth engine for smart city development.

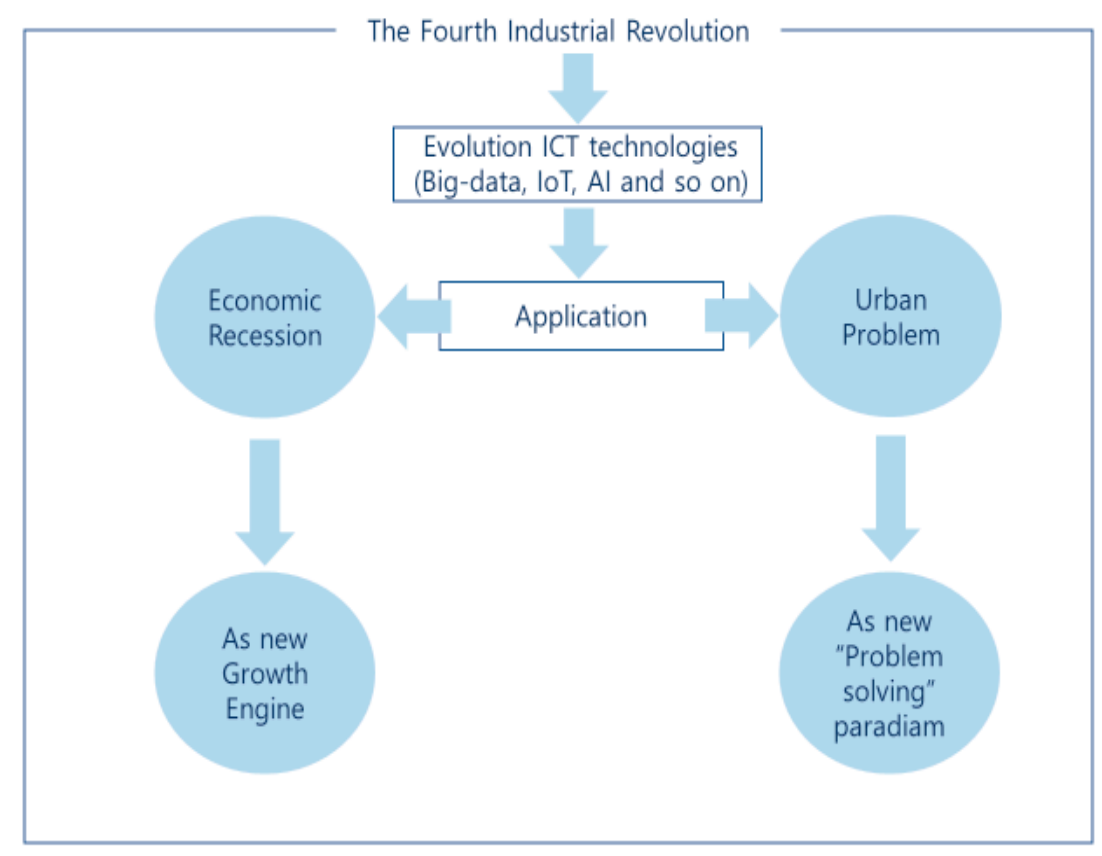

Figure 3. The fourth Industrial Revolution and smart cities.

\subsubsection{Political Will}

Following the flow of this smart city age, the governments of the world are firmly committed to developing smart cities. On 26 November 2013, the European Commission was held in Brussels, Belgium; they initiated a request for participation to establish "Smart City and Community Commitments." They also mentioned that the European Innovation Partnership (EIP) is needed, and the EIP will focus on effective solutions to the challenges facing European cities, smart cities, and communities. The European Commission also announced that it planned to invest approximately $€ 200$ million in smart cities and communities in the 2014-2015 budget of the Horizon 2020 Research and Innovation Program. As a result, there are well-developed smart cities in the Netherlands, Spain, and the United Kingdom (UK). In China, they are looking to urbanization to drive domestic demand growth and future growth. Since 2012, this country has been home to the world's largest smart city business, which was led by the city's rural construction department. It had invested a total of 78 billion dollars as of 2015. To do this, in August 2013, following the announcement of 90 demonstration sites in January, 103 additional sites were added. Japan is also aiming to export smart-related technology overseas. By 2020, it is expected to have an economic effect of 3.2 trillion yen and create more than 60,000 jobs. In Korea, smart cities will be built in the Cheongra and Songdo international cities and Yeongjong Sky cities by 2020, focusing on five areas: transportation, crime prevention, environment, facility management, and urban service provision. In addition, Songdo city will be built as a high-tech business city with ICT convergence through the Songdo City Integrated Operation Center, which had received investments totaling KRW 16.5 billion as of 2014 [43]. Smart cities are being evaluated as new growth engines in response to the recession and the settlement of existing urban problems in the 
flow of the fourth Industrial Revolution. This trend was naturally achieved through policy intentions, and is regarded as a key external factor in the development of smart cities.

The government's efforts to build a smart city are interpreted mainly by the will of the central government (central government's political will). As shown in Figure 4, the policy agenda of the central government is confronted with the local government in the region where the city will be set up, which is related to the policy will of the local government. Even if the central government is strong in the will of the smart city, there are cases where it conflicts with local governments' self-governing laws or regulations, and there are also cases where limitations to the central government's laws and regulations are encountered. The government's policy agenda should always be considered together with the local government's political will.

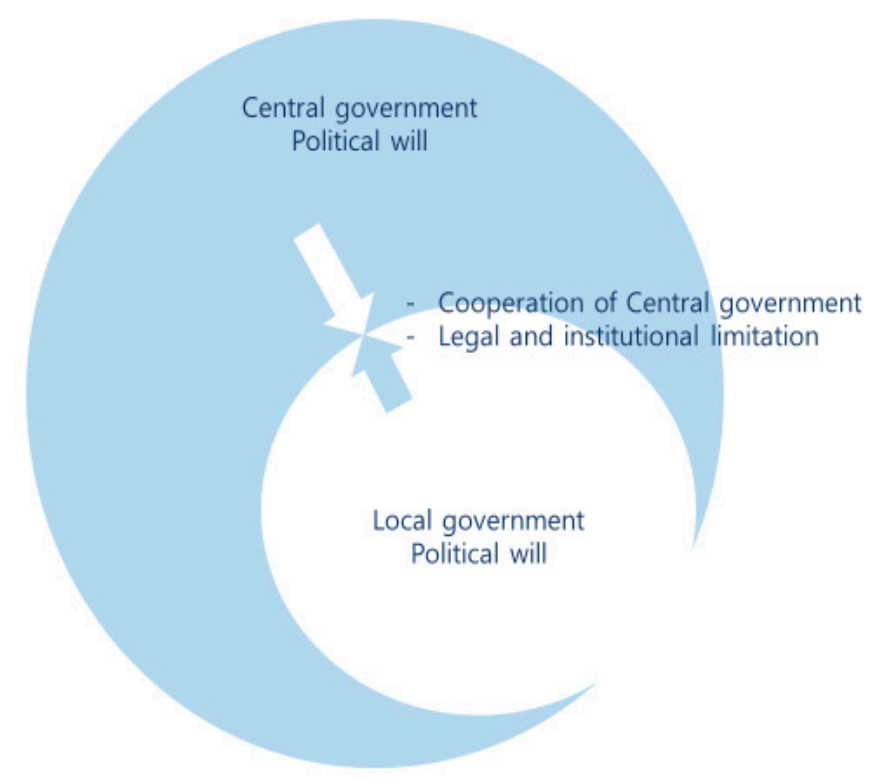

Figure 4. Will conflicts and legal and institutional limitations.

\subsubsection{Stakeholders}

As smart cities are developing, the role of stakeholders directly or indirectly affected by smart cities has also become important. If urban planning-based cities were the product of central government-centered development, smart cities are the product of a combination of various decentralized stakeholders. Smart city project implementation and smart city vision formulation are subject to stakeholder integration, and their close collaboration is integral to the achievement of mutually beneficial end results [44].

As shown in Table 3 above, stakeholders surrounding the smart city can be divided into direct stakeholders and indirect stakeholders. Citizens and city government, government officials on smart city services and infrastructure building, and local enterprises are direct stakeholders. Citizens are the most direct beneficiaries of smart city services. Urban authorities and managers of city governments are the main actors in building smart cities and delivering services to citizens. Local enterprises in a smart city can benefit directly from creating new profits by leveraging smart city infrastructure. Indirect stakeholders include smart city technology and application providers, integrated system builders, and infrastructure service providers and operators. They provide smart city-related technology and infrastructure services in the process of creating value-added outputs and products of a smart city.

Stakeholders are one of the critical external factors for smart cities. In order for smart cities to be successful, harmonization of the direct and indirect stakeholders is important. 
Table 3. Types of stakeholders in smart cities.

\begin{tabular}{cl}
\hline Types & \multicolumn{1}{c}{ Stakeholders } \\
\hline $\begin{array}{c}\text { Direct stakeholders: } \\
\text { city as a customer }\end{array}$ & $\begin{array}{l}\text { Citizens, city authorities, government managers of infrastructure } \\
\text { building and service delivery, local enterprises }\end{array}$ \\
\hline $\begin{array}{c}\text { Indirect stakeholders: } \\
\text { enabling city as a customer }\end{array}$ & $\begin{array}{l}\text { Technology and application providers, system integrators, } \\
\text { infrastructure service providers and operators }\end{array}$ \\
\hline
\end{tabular}

In sum, smart cities have emerged as a means to solve the existing urban problems due to the fourth Industrial Revolution. Smart cities are being developed in various countries, and are recognized as a new economy growth engine. Governments are aware of this, and have shown policy intentions to develop smart cities. The implementation of such policy calls for the harmonization and integration of smart city stakeholders. The fourth Industrial Revolution, Smart City Policy Commitment, and stakeholders are key external elements of smart city building and need to be looked at carefully.

\section{Analysis and Discussion}

\subsection{Survey}

\subsubsection{Data Collection and Expert Survey}

Data was collected from 26 March to 13 April 2018. Twenty experts were selected to elucidate the importance of and priorities in building smart cities. An Analytic Hierarchy Process (AHP) questionnaire was conducted to gather external factors and detailed factors from the experts via e-mail. Twenty experts include professors, civil servants (city-related, smart city-related, etc.), and smart city-related researchers or experts. Their demographic details can be found in Table 4 .

Table 4. Demographics of the research participants.

\begin{tabular}{|c|c|c|c|}
\hline \multicolumn{2}{|c|}{ Sample Characteristics } & \multirow{2}{*}{$\begin{array}{c}\text { Samples } \\
20\end{array}$} & \multirow{2}{*}{$\begin{array}{c}\text { Percentage }(\%) \\
100.0 \%\end{array}$} \\
\hline & & & \\
\hline \multirow{5}{*}{ Age } & $20-30$ & 2 & $10.0 \%$ \\
\hline & $31-40$ & 3 & $15.0 \%$ \\
\hline & $41-50$ & 11 & $55.0 \%$ \\
\hline & $51-60$ & 3 & $15.0 \%$ \\
\hline & Over 60 & 1 & $5.0 \%$ \\
\hline \multirow{3}{*}{ Position } & Academic & 11 & $55.0 \%$ \\
\hline & Civil servant & 1 & $5.0 \%$ \\
\hline & Researcher & 8 & $40.0 \%$ \\
\hline \multirow{4}{*}{ Career length (years) } & Less than 5 & 6 & $30.0 \%$ \\
\hline & $6-10$ & 3 & $15.0 \%$ \\
\hline & $10-20$ & 8 & $40.0 \%$ \\
\hline & Over 20 & 3 & $15.0 \%$ \\
\hline
\end{tabular}

\subsubsection{Relative Importance and Priority Measurement Using the AHP Technique}

In this study, the SPSS 18 package was used to analyze the descriptive statistics and determine their significance and priority. In addition, Microsoft Excel was used to identify the importance and priority of the derived key factors.

In multi-attribute decision making, it is difficult to determine the weight by considering the relative importance of each attribute. For this reason, AHP extracts two attributes and compares them. In order to evaluate the relative importance of the elements in the lower layer from the viewpoint of one attribute in a certain hierarchy, a pair comparison is performed between the evaluation criteria, and the result is represented as a matrix. In pair comparisons, the decision maker's preference for 
evaluation criteria is first expressed and quantified. For this, a reliable evaluation scale is needed, and AHP is using the nine-point scale proposed by Saaty [45]. Table 5 shows examples and paired comparison scales for measuring the relative importance used in the hierarchical analysis procedure for this study.

Table 5. Example survey.

\begin{tabular}{|c|c|c|}
\hline \multicolumn{3}{|c|}{$\begin{array}{l}\text { 1. Meaning of evaluation scale } \\
5 \rightarrow \text { Extremely important, } 4 \rightarrow \text { Very important, } 3 \rightarrow \text { Important, } \\
2 \rightarrow \text { Less important, } 1 \rightarrow \text { Same } \\
\text { (Example 1): A is more important than B }\end{array}$} \\
\hline Item & Rating scale & Item \\
\hline A & 54 (3) 212345 & B \\
\hline \multicolumn{3}{|c|}{ (Example 2): B is more important than A } \\
\hline Item & Rating scale & Item \\
\hline A & 54321234 (5) & B \\
\hline \multicolumn{3}{|c|}{ (Example 3): A and B are the same } \\
\hline Item & Rating scale & Item \\
\hline A & 5432 (1) 2345 & $\mathrm{~B}$ \\
\hline
\end{tabular}

Note: It is important to maintain logical consistency, because the two items that are compared in the survey are interrelated. Therefore, please cooperate to ensure consistency, as shown in the following example. Example: If $\mathrm{A}>\mathrm{B}$ and $\mathrm{B}>\mathrm{C} \rightarrow \mathrm{A}>\mathrm{C}$.

\subsubsection{Reliability Verification through Consistency Analysis}

The reliability analysis of the AHP technique can measure interpersonal judgment error by calculating a consistency ratio (CR) when evaluating the relative importance between each evaluation factor. Generally, the smaller the CR value, the more consistent it is. If the CR value is less than $10 \%$ (0.1), it is judged that the respondent consistently performed a binary comparison $[45,46]$. Table 6 shows the verification of consistency smart city decision factors and sub-items.

Table 6. Verification of consistency of smart city decision factors and sub-items. ICT: information and communication technology.

\begin{tabular}{|c|c|c|c|}
\hline & Top Items & Sub-Items & Details \\
\hline \multirow{14}{*}{$\begin{array}{c}\text { Smart City } \\
\text { Main } \\
\text { Factors }\end{array}$} & \multirow{7}{*}{ Internal factor } & \multirow{2}{*}{$\begin{array}{c}\text { Citizen } \\
\text { participation }\end{array}$} & Needs of residents expressed through public hearings \\
\hline & & & $\begin{array}{l}\text { The existence of creative communication channels for } \\
\text { city building }\end{array}$ \\
\hline & & \multirow{2}{*}{ Leadership } & Understanding of ICT technology \\
\hline & & & Political capacity of the head of the local government \\
\hline & & \multirow{2}{*}{ Infrastructural } & Technology infrastructure \\
\hline & & & Human infrastructure \\
\hline & & CR: 0.0214 & CR: 0.0119 \\
\hline & \multirow{7}{*}{ External Factors } & \multirow{2}{*}{$\begin{array}{l}\text { The fourth } \\
\text { Industrial } \\
\text { Revolution }\end{array}$} & A paradigm to solve urban problems \\
\hline & & & Core engine of new growth \\
\hline & & \multirow{2}{*}{ Political will } & Revision or reorganization of legal system \\
\hline & & & Local governments' willingness to cooperate \\
\hline & & \multirow{2}{*}{ Stakeholders } & Direct stakeholders \\
\hline & & & Indirect stakeholders \\
\hline & & CR: 0.0397 & CR: 0.0328 \\
\hline
\end{tabular}




\subsection{Analyzing the Sub-Items and Details Based on Importance and Priority}

\subsubsection{Sub-Item Analysis: The Relative Importance and Priority of the Internal Factors}

As shown in Table 7, The sub-items consisted of citizen participation, leadership, and infrastructure; they were ranked in order of priority. Citizen participation was highest at 0.448 , leadership was 0.370 , and infrastructure was 0.181 . The most important internal factor of a smart city is that the experts highly appreciate the participation of citizens in the formation of a smart city, which shows that it is desirable to develop citizen participation and legal support in smart city development.

Table 7. The relative importance and priority of the internal factors.

\begin{tabular}{ccc}
\hline Internal Factors & $\begin{array}{c}\text { Relative } \\
\text { Importance }\end{array}$ & Priority \\
\hline Citizen participation & 0.448 & 1 \\
Leadership & 0.370 & 2 \\
Infrastructural & 0.181 & 3 \\
\hline
\end{tabular}

Consistency Index: 0.0214 .

\subsubsection{Sub-Item Analysis: The Relative Importance and Priority of the External Factors}

As a result of the analysis of external factors shown in Table 8, political will was ranked first with 0.468 , stakeholders were ranked second with 0.273 , and the fourth Industrial Revolution was ranked third with 0.259 .

Although smart cities emerged and developed in the flow of the fourth Industrial Revolution, it was judged by the experts that their development will be delayed without governments' political will. Also, the role of stakeholders in smart cities was seen as more important than the flow of the fourth Industrial Revolution.

Table 8. The relative importance and priority of the external factors.

\begin{tabular}{ccc}
\hline Internal Factors & Relative Importance & Priority \\
\hline The fourth Industrial Revolution & 0.259 & 3 \\
Political will & 0.468 & 1 \\
Stakeholders & 0.273 & 2 \\
\hline
\end{tabular}

Consistency Index: 0.0119.

\subsubsection{Analysis of the Relative Importance and Priority of Details from the Internal Factors}

The results regarding the relative importance and priority of details from the internal factors are shown in Table 9. The details of the sub-items should be further refined to reflect the needs of residents through public hearings that determine the type of private activity policies in the process of implementing smart cities, such as public hearings, bottom-up approaches, and life experiments. The presence of creative communication channels was ranked first. Leadership includes innovative, open, and political leadership, and understanding of the political process in local governance, as well as ICT knowledge. Finally, the infrastructure items were classified into smart technology infrastructure including smart buildings, smart sensors, IoT, networks, artificial intelligence, and human infrastructure for providing smart city services.

The experts rated the existence of creative communication channels for city building as 0.24 , the needs of residents expressed through public hearings as 0.229 , understanding of IT technology as 0.162 , political capacity of the head of the local government as 0.145 , technology infrastructure as 0.117 , and human infrastructure as 0.107 . The high rating for the existence of creative communication 
channels for city building is in line with the significant assessment of citizens' participation in the evaluation of sub-items. The experts rated citizens and participation as the most important internal factors of smart cities.

Table 9. The relative importance and priority of details from the internal factors. IT: information technology.

\begin{tabular}{ccc}
\hline Internal Detail Factors & Relative Importance & Priority \\
\hline Needs of residents expressed through public hearings & 0.229 & 2 \\
The existence of creative communication channels for city building & 0.240 & 1 \\
Understanding of IT & 0.162 & 3 \\
Political capacity of the head of the local government & 0.145 & 4 \\
Technology infrastructure & 0.117 & 5 \\
Human infrastructure & 0.107 & 6 \\
\hline
\end{tabular}

Consistency Index: 0.0119 .

\subsubsection{Analysis of the Relative Importance and Priority of Details from the External Factors}

The fourth Industrial Revolution transformed the paradigm for solving existing urban problems, and is regarded as one of the key elements of smart cities. In addition, we expect to be able to solve existing problems more efficiently by integrating various technologies into cities as a key engine of new growth during the recession.

Smart cities that have fused with next-generation technologies have emerged, and various smart city development policies are underway. Depending on the revision or reorganization of the legal system and the cooperation of local governments, smart cities can settle quickly.

While smart cities are emerging as a result of government-led policies, they are not sustainable without stakeholders, who are a major external component of smart cities' development. Stakeholders of smart cities include direct stakeholders (governments, civic groups, urban and local businesses, etc.) and indirect stakeholders (service providers such as technology/infrastructure providers and system builders).

As shown in Table 10, the experts ranked the revision or reorganization of legal systems first with 0.221 , direct stakeholders second with 0.202 , a paradigm to solve urban problems third with 0.169 , local governments' willingness to cooperate fourth with 0.161 , a core engine of new growth fifth with 0.151, and finally, indirect stakeholders were rated sixth with 0.096 .

In addition, the importance of the internal factor of citizen participation and communication was emphasized, while governments' policy intentions were the most important external factor. This implies that an important step toward smart city development is revising and adjusting the current laws so as to not hinder smart cites' development and reflect the governments' political will.

Table 10. The relative importance and priority of details from the external factors.

\begin{tabular}{ccc}
\hline External Detail Factors & Relative Importance & Priority \\
\hline A paradigm to solve urban problems & 0.169 & 3 \\
Core engine of new growth & 0.151 & 5 \\
Revision or reorganization of legal system & 0.221 & 1 \\
Local governments' willingness to cooperate & 0.161 & 4 \\
Direct stakeholders & 0.202 & 2 \\
Indirect stakeholders & 0.096 & 6 \\
\hline
\end{tabular}

Consistency index: 0.0328 . 


\section{Policy Implications and Conclusions}

This study investigated the determinant factors that influence smart city development, and suggested that smart city development include citizen participation with multi-communication channels in the process of smart city building. The results of the study can be summarized as follows:

- First, as for the relative importance of the internal factors, the most important factor was citizen involvement (0.448). Leadership (0.370) and infrastructure (0.181) were next. The experts said that smart cities could not move in the right direction without citizen participation. Leadership by local governments regarding urban policy was also seen as an important factor. The technical and human infrastructure inside the city was relatively insignificant.

- Second, the importance of internal factors was examined in terms of the existence of creative communication channels for city building $(0.240)$, the needs of residents expressed through public hearings (0.229), understanding of ICT technology (0.162), technology infrastructure (0.117), and human infrastructure (0.107).

- Finally, as for the relative importance of the external factors, the highest ranked was political will (0.468), followed by stakeholders (0.273) and the fourth Industrial Revolution (0.259). In the lower priority external factors, first was the revision or reorganization of the legal system (0.221), followed by direct stakeholders (0.202), a paradigm to solve urban problems (0.169), local governments' willingness to cooperate (0.161), a core engine of new growth (0.151), and indirect stakeholders (0.096).

This study suggests the following policy alternatives:

- First, in order to build better smart cities, the processes of encouraging citizen participation and establishing various communication channels are vital. The "smart city" label is not limited to cities that simply adopt advanced technology. The ultimate goal of smart city development is to enhance the quality of life of individuals, families, and local people through advanced ICT, rather than the development of advanced technologies themselves. Therefore, it can be said that a bottom-up policy approach is required, rather than a top-down one, in the process of building a smart city. The people who best know the characteristics and problems of an area are its residents and citizens. Citizen participation is the most important factor and cannot be excluded from policy alternatives in smart city development to solve various urban problems. It would be better to create a smart city with ways to communicate with the public and listen to the needs of citizens and implement solutions in conjunction with policies.

- Second, the participation of citizens should be guaranteed based on cooperative support between central and local governments. As the panel experts in this study stated, political will accompanied by strong support is a critical factor in determining a smart city's development. The central government should formulate laws and regulations that minimize the adverse effects of smart city technology adoption while mitigating excessive regulations that restrict the development of new technologies. In order to do so, the government should act as a volunteer, catalyst, and mediator, linking the central government with private enterprises, as well as with civil society. In addition, governance cooperation should be established between central and local governments, civil society, and private companies, including direct and indirect stakeholders, in order to suggest the right direction for smart city development.

- Third, although the importance of infrastructure factors was relatively low, a smart city's construction depends heavily on the application and development of advanced ICT in the beginning stage. Therefore, investment in the research and development of smart city technology applications should be done in parallel. Similarly, the development and commercialization of technologies such as smart buildings, smart sensors, smart traffic, and smart disaster management need to be pursued in order to connect diverse functions such as neural networks throughout the city. At the same time, it is necessary to cultivate smart talents to utilize smart technologies in the 
right place and utilize them in city policy on the whole. Administrative tasks in smart cities are likely to be reexamined and redefined due to the introduction of new technologies. Therefore, administrative manpower will also be required in the form of smart talent with the ability to predict, create, and communicate.

- Finally, although this AHP panel study was conducted with an expert group to derive the determinants of smart cities and evaluate their priority, the size and scope of the sample were limited. In future research, it would be desirable to target smart city experts in a wider range of fields, such as technology researchers, engineers, and frontline administrative officials related to smart cities. The balanced scorecard (BSC) method needs to be employed in the future study to find out the causality between lagging (results) and leading (future) indicators on the basis of vision and strategies in building a smart city. Further, a field survey needs to be conducted for increasing the level of validity of the study, as well as the generalizability of the empirical results.

Author Contributions: Seunghwan Myeong (co-first author/correspondent author) designed a research framework and wrote the paper with editing; Yuseok Jung (co-first author) performed a survey and analyzed the data; Eunuk Lee (co-first author) updated a literature review and re-conducted a data analysis.

Funding: This work was supported by the Inha University in South Korea.

Conflicts of Interest: The authors declare no conflict of interest.

\section{References}

1. UN World Urbanization Prospects: The 2014 Revision. pp. 1-32. Available online: https://esa.un.org/ unpd/wup/publications/files /wup2014-report.pdf (accessed on 19 July 2018).

2. R\&D Information Center in Korea. IoT-Based Smart City Construction Status and Actual Condition Analysis Trend by Industry Technology; R\&D Information Center in Korea: Seoul, Korea, 2017; pp. 1-682.

3. Smart Cities Navigant Research 2016. Available online: https://www.navigantresearch.com/research/ smart-cities (accessed on 19 July 2018).

4. Albino, V.; Berardi, U.; Dangelico, R.M. Smart cities: Definitions, dimensions, performance, and initiatives. J. Urban Technol. 2015, 22, 3-21. [CrossRef]

5. Alawadhi, S.; Aldama-Nalda, A.; Chourabi, H.; Gil-Garcia, J.R.; Leung, S.; Mellouli, S.; Nam, T.; Pardo, T.A.; Scholl, H.J.; Walker, S. September. Building understanding of smart city initiatives. In Proceedings of the International Conference on Electronic Government, Kristiansand, Norway, 3-6 September 2012; pp. 40-53.

6. Nam, T.; Pardo, T.A. Smart city as urban innovation: Focusing on management, policy, and context. In Proceedings of the 5th International Conference on Theory and Practice of Electronic Governance, Tallinn, Estonia, 26-28 September 2011; pp. 185-194.

7. Komninos, N. Intelligent Cities: Innovation, Knowledge Systems and Digital Spaces; Routledge: Abingdon, UK, 2013; pp. 1-320.

8. Shapiro, J.M. Smart cities: Quality of life, productivity, and the growth effects of human capital. Rev. Econ. Stat. 2006, 88, 324-335. [CrossRef]

9. Deakin, M. (Ed.) Smart Cities: Governing, Modelling and Analyzing the Transition; Routledge: Abingdon, UK, 2013; pp. 1-236.

10. Pereira, Â.G.; Quintana, S.C. From technocratic to participatory decision support systems: Responding to the new governance initiatives. J. Geogr. Inf. Decis. Anal. 2002, 6, 95-107.

11. Hollands, R.G. Will the real smart city please stand up? Intelligent, progressive or entrepreneurial? City 2008, 12, 303-320. [CrossRef]

12. Hall, R.E.; Bowerman, B.; Braverman, J.; Taylor, J.; Todosow, H.; Von Wimmersperg, U. The Vision of a Smart City; Brookhaven National Lab: Upton, NY, USA, 2000.

13. Bakıc1, T.; Almirall, E.; Wareham, J. A smart city initiative: The case of Barcelona. J. Knowl. Econ. 2013, 4, 135-148.

14. Giffinger, R.; Gudrun, H. Smart cities ranking: An effective instrument for the positioning of the cities? ACE Archit. City Environ. 2010, 4, 7-26.

15. Florida, R. Cities and the Creative Class; Routledge: Abingdon, UK, 2005; pp. 1-17. 
16. Yigitcanlar, T.; Kamruzzaman, M.; Buys, L.; Ioppolo, G.; Sabatini-Marques, J.; Costa, E.; Yun, J. Understanding 'smart cities': Intertwining development drivers with desired outcomes in a multidimensional framework. Cities 2018. [CrossRef]

17. World Economic Forum. 5 Ways to Make Our Cities Smarter. 2015. Available online: https:/ /www.weforum. org/agenda/2015/10/5-ways-to-make-our-cities-smarter/ (accessed on 19 July 2018).

18. Oh, Y.J. Policy tasks and strategies for low-carbon energy saving urban planning. In Proceedings of the Korea Regional Development Institute Conference, Seoul, Korea, 30 August 2010; pp. 47-66.

19. Lim, B.-H.; Lee, S.-Y.; Lee, G.-H. A Study on the Priority of Energy Saving urban Planning elements using the AHP technique. Korea Dev. Inst. 2013, 25, 217-232.

20. Jeong, D.G. A Study on a Smart Green City Energy Integrated Control Platform Based on IoT Technology. Ph.D. Thesis, Sungkyunkwan University, Seoul, Korea, 2015; pp. 1-140.

21. Oh, D.S. A study on a smart green city planning technique of energy: Focused on the actual condition of a happy city. Korea Inst. Sci. Technol. 2015, 16, 6368-6375.

22. Gang, Y.S. Smart City and Traffic Part Strategy; Korea Transport Institute: Seoul, Korea, 2017; pp. 21-26.

23. Stefansson, G.; Lumsden, K. Performance issues of smart transportation management systems. Int. J. Prod. Perform. Manag. 2008, 58, 55-70. [CrossRef]

24. Sherly, J.; Somasundareswari, D. Internet of things based smart transportation systems. Int. Res. J. Eng. Technol. 2015, 2, 1207-1210.

25. Lécué, F.; Tallevi-Diotallevi, S.; Hayes, J.; Tucker, R.; Bicer, V.; Sbodio, M.; Tommasi, P. Smart traffic analytics in the semantic web with STAR-CITY: Scenarios, system and lessons learned in Dublin City. In Web Semantics: Science, Services and Agents on the World Wide Web; Elsevier: Dublin, Ireland, 2014; Volume 27, pp. $26-33$.

26. Batty, M. Big data, smart cities and city planning. Dialogues Hum. Geogr. 2013, 3, 274-279. [CrossRef] [PubMed]

27. Zygiaris, S. Smart city reference model: Assisting planners to conceptualize the building of smart city innovation ecosystems. J. Knowl. Econ. 2013, 4, 217-231. [CrossRef]

28. Anthopoulos, L.G.; Vakali, A. Urban planning and smart cities: Interrelations and reciprocities. In The Future Internet Assembly; Springer: Berlin, Heidelberg, 2012; pp. 178-189.

29. Chen, C.; Duan, S.; Cai, T.; Liu, B.; Hu, G. Smart energy management system for optimal microgrid economic operation. IET Renew. Power Gener. 2011, 5, 258-267. [CrossRef]

30. Lund, H.; Andersen, A.N.; Østergaard, P.A.; Mathiesen, B.V.; Connolly, D. From electricity smart grids to smart energy systems-a market operation based approach and understanding. Energy 2012, 42, 96-102. [CrossRef]

31. Saaty, T.L. The Analytic Hierarchy Process: A new approach to deal with fuzziness in architecture. Archit. Sci. Rev. 1982, 25, 64-69. [CrossRef]

32. Kang, Y.-G. An exploratory study on the conceptual framework of self-management civic participation. Korea Autonomous Adm. J. 2008, 22, 141-150.

33. Margerum, R.D. Evaluating collaborative planning: Implications from an empirical analysis of growth management. J. Am. Plan. Assoc. 2002, 68, 179-193. [CrossRef]

34. Kim, H.-J. Smart era, expansion and transformation of urban planning. Space Soc. 2017, 59, 86-127.

35. Lee, S.-M. Analysis of the leadership of the head of the local authority by the success of the Lifelong Learning City Project. J. GRI Res. 2012, 14, 187-219.

36. Neirotti, P.; De Marco, A.; Cagliano, A.C.; Mangano, G.; Scorrano, F. Current trends in smart city initiatives: Some stylised facts. Cities 2014, 38, 25-36. [CrossRef]

37. Washburn, D.; Sindhu, U.; Balaouras, S.; Dines, R.A.; Hayes, N.; Nelson, L.E. Helping CIOs understand "smart city" initiatives. Growth 2009, 17, 1-7.

38. Taylor Buck, N.; While, A. Competitive urbanism and the limits to smart city innovation: The UK Future Cities initiative. Urban Stud. 2017, 54, 501-519. [CrossRef]

39. Moir, E.; Moonen, T.; Clark, G. What Are Future Cities? Origins, Meanings and Use; Working Paper 20. The Business of Cities for the Foresight Future of Cities Project and the Future Cities Catapult; Government Office for Science: London, UK, 2014. Available online: https://www.gov.uk/government/uploads/system/ uploads/attachment_data/file/429125/future-cities-global-agenda.pdf (accessed on 22 July 2018).

40. Toporkoff, S. ICT convergence and Europe's digital agenda 2010-2020. In The Real Issues of the Middle East and the Arab Spring; Springer: New York, NY, USA, 2013; pp. 315-330. 
41. Schwab, K. The Fourth Industrial Revolution: What It Means, How to Respond", WEF Global Agenda, Fourth Industrial Revolution. Available online: https:/ / www.weforum.org/agenda/2016/01/the-fourthindustrial-revolution-what-it-means-and-how-torespond/ (assessed on 22 July 2018).

42. Jaewon, P.C. XnTree, United Kingdom. EROPA. 2017. Available online: https://www.eropa.co/ public-sector-transformations /4th-industrial-revolution-and-smart-city-open-innovation (accessed on 19 July 2018).

43. Korea Communications Agency. Smart City of Major Countries around the World Analysis Case; Policy Research Division Fusion Policy Research Department in Korea: Seoul, Korea, 2014; pp. 58-69.

44. Smart City Stakeholders: Stakeholders Analysis, SMART CITY SOLUTIONS. Available online: http:/ / www. tronicsmartcity.com/smart-city-components/smart-city-stakeholders/ (accessed on 19 July 2018).

45. Vargas, L.G. An overview of the analytic hierarchy process and its applications. Eur. J. Oper. Res. 1990, 48, 2-8. [CrossRef]

46. Park, G.-Y. A Study on Development Plans for Citizen Participatory Budgeting of Local Government Focus on Relative Importance and Priorities Based on AHP. Ph.D. Thesis, Bae Jae University, Daejeon, South Korea, 2011; p. 116.

(C) 2018 by the authors. Licensee MDPI, Basel, Switzerland. This article is an open access article distributed under the terms and conditions of the Creative Commons Attribution (CC BY) license (http:/ / creativecommons.org/licenses/by/4.0/). 